\title{
Professores: quem são, onde trabalham, quanto ganham
}

Guilherme Hirata ${ }^{\text {a }}$ João Batista Araujo e Oliveira ${ }^{b}$ Talita de Moraes Mereb c

\section{Resumo}

Professores constituem um dos componentes mais relevantes no processo educacional. O perfil, a remuneração, as condições de trabalho e a forma de atuação dos professores contribuem de forma significativa para o desempenho dos alunos. O presente artigo analisa os dados mais atuais disponíveis sobre os professores brasileiros: quem são, onde trabalham, quanto ganham, que impacto produzem. Essas são informações essenciais para entender a realidade, tendências e possibilidades de intervenção. O estudo se divide em três partes. Na primeira, caracteriza a quantidade de professores por nível de ensino e apresenta dados a respeito de seu perfil. Na segunda parte, apresenta dados referentes à remuneração e às tendências recentes de aumento dos salários. Na terceira, discute o impacto real e potencial de professores em um sistema de ensino. $\mathrm{O}$ artigo conclui com reflexões a respeito de possíveis caminhos para aumentar a eficiência e a eficácia das redes públicas de ensino, e, possivelmente, também da rede privada.

Palavras-chave: Educação básica. Professores. Salário.

\section{Introdução}

As políticas públicas necessitam de diagnósticos precisos para serem formuladas e ganharem eficiência. $\mathrm{O}$ objetivo deste artigo é traçar um perfil do professor no Brasil, oferecendo informações que podem servir como insumos para elaborar uma agenda pública para melhorar o sistema de educação básica. Uma das premissas de uma tal agenda é a necessidade de tornar atraente a profissão de professor da educação básica. Para tanto, é necessário conhecer os dados relativos aos professores, assim como entender sua composição.

\footnotetext{
a IDados, Rio de Janeiro, RJ, Brasil

b Instituto Alfa e Beto, Rio de Janeiro, RJ, Brasil

c IDados, Rio de Janeiro, RJ, Brasil
} 
O Gráfico 1 mostra a evolução, de 2007 a 2017, do número de professores na educação básica - isto é, educação infantil, ensino fundamental, ensino médio, educação profissional, educação de jovens e adultos e educação especial -, responsáveis pela regência de classe, ou seja, docentes. Os dados do Instituto Nacional de Estudo e Pesquisas Educacionais Anísio Teixeira (Inep/MEC) mostram que o número de professores cresceu no período, apresentando uma desaceleração a partir de 2014. Em contraste, o gráfico também mostra que a matrícula de alunos da educação básica sofreu uma queda contínua entre 2008 e 2015.

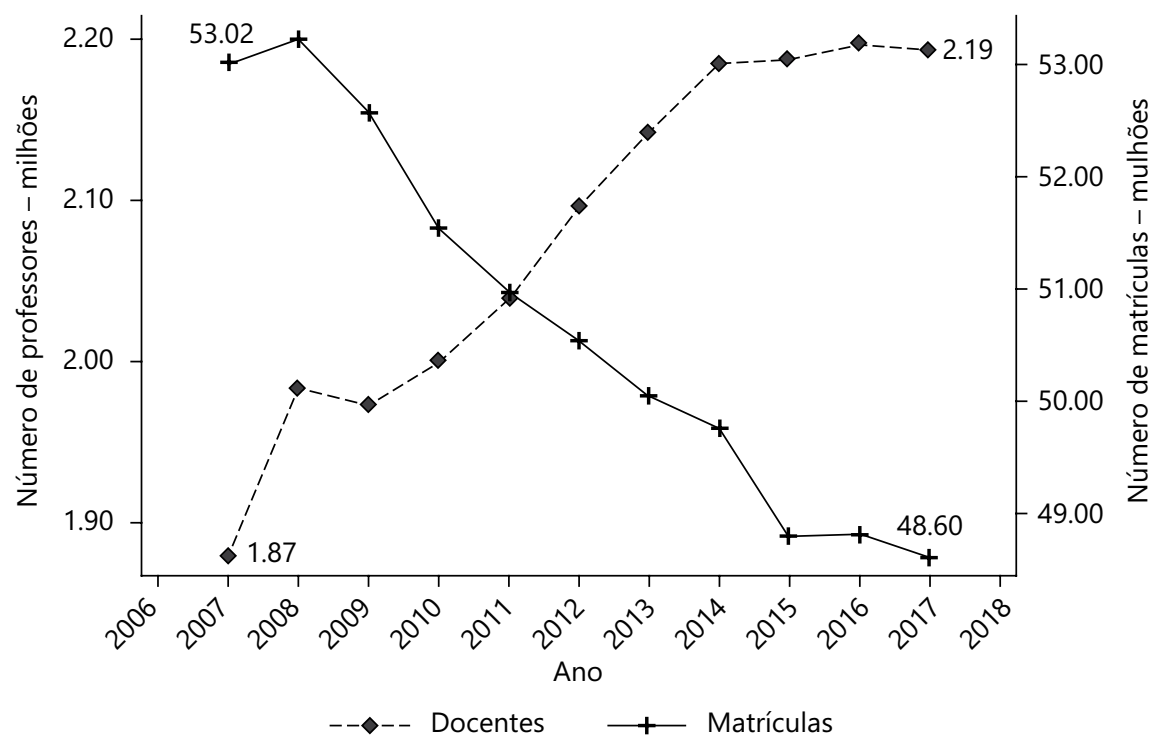

Gráfico 1. Evolução da quantidade de docentes e matrículas na educação básica no Brasil, de 2007 a 2017. Fonte: MEC/INEP. Elaboração IDados. 2018.

No último ano da série histórica, 2017, havia 2.192.224 professores atendendo 48.608.093 matrículas. O presente artigo procura entender, com base nos dados de 2017, quem são os atuais professores da educação básica do Brasil, sua eficiência no atendimento aos alunos e quanto eles ganham. Nesse sentido, este artigo complementa a literatura sobre o tema ao apresentar dados mais recentes que outros estudos que traçaram o perfil dos professores, como Barros, Mendonça e Blanco (2001) e Andrade et al. (2004). Tais estudos mostraram que, tipicamente, o docente na década de 1990 era mulher, na faixa dos 30 anos de idade, e que possuía apenas o ensino médio completo. Barros, Mendonça e 
Blanco (2001) mostram também que, de modo geral, o salário dos professores das redes públicas era menor que o da rede privada e de outras ocupações no mercado de trabalho. Mais recentemente, Barbosa Filho, Pessôa e Afonso (2009) compararam a renda dos professores no setor público e privado, incluindo salários e aposentadorias futuras, e encontraram que os professores das redes públicas auferiam maiores salários.

Além de analisar o perfil dos professores, a literatura também apresenta evidências sobre a relação entre perfil e desempenho escolar dos alunos, abordando, além das características socioeconômicas e demográficas, a forma de atuação dos professores, como práticas pedagógicas, por exemplo (DEMO, 2010; FAJARDO; MINAYO; MOREIRA, 2010; PIMENTEL; PALAZZO; OLIVEIRA, 2009; RODRIGUES, 2017).

O artigo está dividido em cinco seções, além dessa introdução. A segunda seção descreve quem são e onde trabalham os professores e a seção 3 aborda a eficiência de atendimento. A seção 4 estuda os salários dos professores, enquanto a seção 5 situa os resultados encontrados no contexto de políticas públicas. A seção 6 apresenta as conclusões.

\section{Quem são os professores, quantos são e onde trabalham}

Em 2017, as redes públicas concentravam, de maneira bem expressiva, os docentes em todas as etapas de ensino (Gráfico 2). O total de professores difere do apresentado no Gráfico 1 porque o Gráfico 2 considera o vínculo do professor por etapa e rede, e, como há professores que lecionam em mais de uma etapa e/ou rede, eles são contabilizados mais de uma vez.

Nas redes públicas, os anos finais do ensino fundamental apresentam o maior número de professores, totalizando 631 mil. Ao contrário do que ocorre nas redes públicas, o pico da distribuição dos professores na rede privada se dá nos anos iniciais do ensino fundamental, nos quais há 178 mil docentes. Destaca-se também a atuação de 234 mil professores das redes públicas na educação de jovens e adultos (EJA), enquanto na rede privada, apenas 7 mil professores atuam nessa modalidade.

Do total de professores da educação básica brasileira, 91,4\% trabalham em uma única rede de ensino (2,0 milhões), 78,5\% lecionam em uma única escola (1,7 milhões) e 72,5\% trabalham em uma única etapa de ensino (Gráfico 3). Esse resultado revela que, majoritariamente, os professores trabalham em uma única rede e escola. 


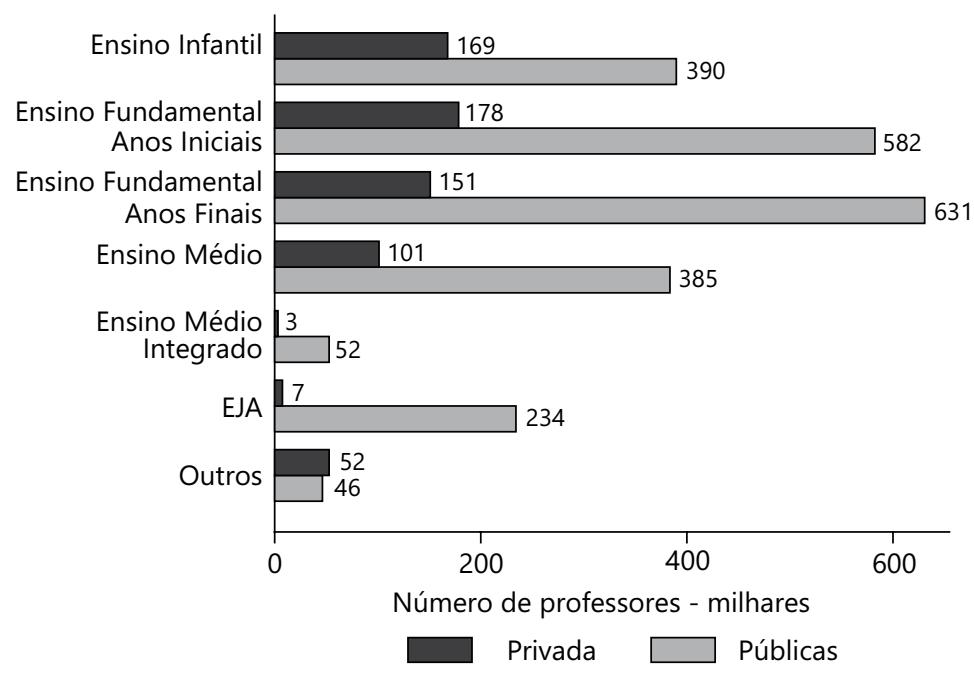

Nota: "Outros" engloba educação especial e educação profissional

Gráfico 2. Docentes por rede e etapa de ensino no Brasil, 2017. Fonte: MEC/INEP. Elaboração IDados. 2018.
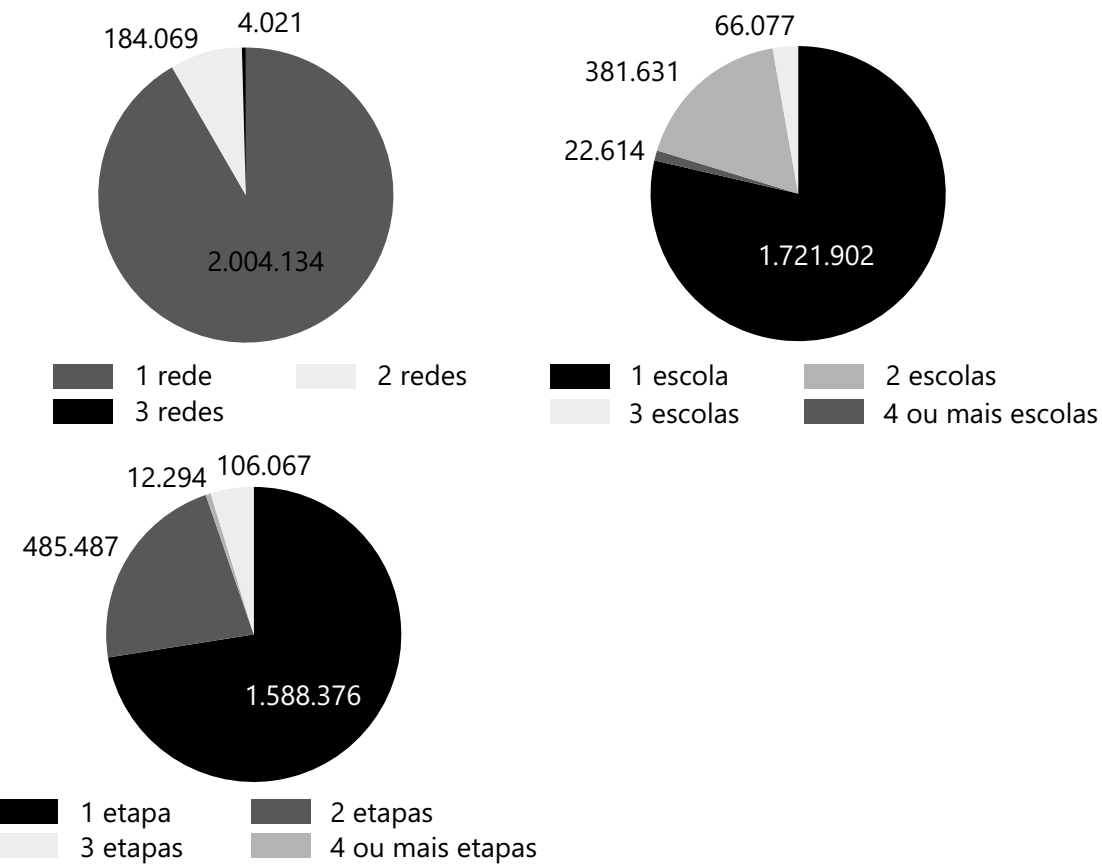

Gráfico 3. Número de professores que trabalham em uma ou mais redes de ensino, escolas e etapas de ensino - Brasil, 2017. Fonte: MEC/INEP. Elaboração IDados. 2018. 
Os dados apresentados no Quadro 1, a seguir, mostram que a maioria dos professores da educação básica nas redes privada e públicas, tomados em conjunto, trabalha em um único turno. No entanto, há uma certa heterogeneidade entre etapas de ensino e redes. No caso das redes públicas, o percentual de professores que trabalha em um único turno é menor no ensino médio e anos finais do ensino fundamental $(62,2 \%$ e $70,6 \%)$ do que na educação infantil e anos iniciais $(87,8 \%$ e $80,5 \%)$. Por outro lado, na rede privada, é no ensino médio que se observa a maior porcentagem de professores trabalhando em um único turno, $91,2 \%$, seguido do ensino infantil, $85,5 \%$. Nota-se, ainda, que o percentual mais expressivo de professores que trabalha em três turnos foi observado nas redes públicas no ensino médio, $6 \%$.

Quadro 1.- Porcentagem de professores que trabalham em um ou mais turnos Brasil, 2017

\begin{tabular}{|l|c|c|c|c|c|c|}
\hline \multirow{2}{*}{ Ciclo } & \multicolumn{7}{|c|}{ Percentual do total } \\
\cline { 2 - 7 } & \multicolumn{2}{|c|}{ Um turno } & \multicolumn{2}{c|}{ Dois turnos } & \multicolumn{2}{c|}{ Três Turnos } \\
\cline { 2 - 7 } & $\begin{array}{c}\text { Redes } \\
\text { Públicas }\end{array}$ & $\begin{array}{c}\text { Rede } \\
\text { Privada }\end{array}$ & $\begin{array}{c}\text { Redes } \\
\text { Públicas }\end{array}$ & $\begin{array}{c}\text { Rede } \\
\text { Privada }\end{array}$ & $\begin{array}{c}\text { Redes } \\
\text { Públicas }\end{array}$ & $\begin{array}{c}\text { Rede } \\
\text { Privada }\end{array}$ \\
\hline Educação Infantil & 87,8 & 85,5 & 12,2 & 14,5 & 0,0 & 0,0 \\
\hline $\begin{array}{l}\text { Ensino Fundamental } \\
\text { - Anos Iniciais }\end{array}$ & 80,5 & 73,2 & 19,5 & 26,8 & 0,0 & 0,0 \\
\hline $\begin{array}{l}\text { Ensino Fundamental } \\
\text { - Anos Finais }\end{array}$ & 70,6 & 79,9 & 29,0 & 20,1 & 0,4 & 0,0 \\
\hline Ensino Médio & 62,2 & 91,2 & 31,8 & 8,6 & 6,0 & 0,2 \\
\hline $\begin{array}{l}\text { Ensino Médio - } \\
\text { Integrado }\end{array}$ & 82,3 & 92,9 & 17,4 & 7,1 & 0,3 & 0,0 \\
\hline EJA & 93,8 & 80,8 & 5,6 & 14,8 & 0,6 & 4,3 \\
\hline Outros & 82,8 & 70,8 & 15,3 & 24,8 & 1,9 & 4,3 \\
\hline
\end{tabular}

Fonte: MEC/Inep. Elaboração: IDados. 2018.

Nota: "Outros" engloba educação especial e educação profissional.

O Quadro 2 apresenta as caraterísticas sociodemográficas dos professores. Para cada rede e etapa de ensino são apresentadas as porcentagens de professores com educação superior, a porcentagem de mulheres, a porcentagem de brancos e a idade média.

Em sua maioria, o conjunto de professores nas redes privada e públicas possui formação superior em todas as etapas de ensino, sendo que a porcentagem de 
Quadro 2. Perfil dos professores no Brasil por sexo, raça/cor, idade e escolaridade, 2017

\begin{tabular}{|l|c|c|c|c|c|c|c|c|}
\hline \multirow{2}{*}{} & \multicolumn{6}{|c|}{ Percentual do total } & \multicolumn{2}{c|}{} \\
\cline { 2 - 8 } & $\begin{array}{c}\text { Educação } \\
\text { Superior }\end{array}$ & \multicolumn{2}{c|}{ Mulheres } & \multicolumn{2}{c|}{ Brancos } & \multicolumn{2}{c|}{ Idade } \\
\cline { 2 - 8 } & $\begin{array}{c}\text { Redes } \\
\text { Públicas }\end{array}$ & $\begin{array}{c}\text { Rede } \\
\text { Privada }\end{array}$ & $\begin{array}{c}\text { Redes } \\
\text { Públicas }\end{array}$ & $\begin{array}{c}\text { Rede } \\
\text { Privada }\end{array}$ & $\begin{array}{c}\text { Redes } \\
\text { Públicas }\end{array}$ & $\begin{array}{c}\text { Rede } \\
\text { Privada }\end{array}$ & $\begin{array}{c}\text { Redes } \\
\text { Públicas }\end{array}$ & $\begin{array}{c}\text { Rede } \\
\text { Privada }\end{array}$ \\
\hline Educação Infantil & 73,2 & 53,0 & 96,5 & 97,0 & 57,7 & 61,5 & 40,8 & 36,4 \\
\hline $\begin{array}{l}\text { Ens. Fundamental } \\
\text { - Anos Iniciais }\end{array}$ & 79,6 & 64,7 & 88,7 & 89,4 & 54,6 & 63,1 & 42,2 & 38,6 \\
\hline $\begin{array}{l}\text { Ens. Fundamental } \\
\text { - Anos Finais }\end{array}$ & 85,9 & 83,8 & 70,0 & 62,3 & 54,8 & 67,5 & 41,7 & 38,8 \\
\hline Ensino Médio & 94,4 & 89,5 & 63,6 & 48,0 & 63,2 & 72,1 & 42,4 & 39,9 \\
\hline $\begin{array}{l}\text { Ensino Médio - } \\
\text { Integrado }\end{array}$ & 96,5 & 84,9 & 46,4 & 46,0 & 69,0 & 67,6 & 41,1 & 39,6 \\
\hline EJA & 84,9 & 87,7 & 65,1 & 56,0 & 48,8 & 58,2 & 42,1 & 40,2 \\
\hline Outros & 94,8 & 85,0 & 52,9 & 61,5 & 72,0 & 72,3 & 42,3 & 40,6 \\
\hline
\end{tabular}

Fonte: MEC/INEP. Elaboração IDados. 2018.

Nota: "Outros" engloba educação especial e educação profissional.

professores com essa formação aumenta de acordo com a etapa. As redes públicas têm percentuais mais altos de professores com formação superior em quase todos os níveis, exceto no EJA. Os professores, 53,0\% dos de educação infantil possuem graduação completa, nas públicas são $73,2 \%$. A diferença é consideravelmente menor no ensino médio, onde $89,5 \%$ dos professores da rede privada têm curso superior completo, contra $94,4 \%$ nas públicas.

Os professores são, majoritariamente, mulheres, com maior taxa de participação na educação infantil e nos anos iniciais do ensino fundamental. A participação de mulheres diminui nas etapas seguintes, mas elas continuam sendo maioria. Apenas no ensino médio, na rede privada e no ensino médio integrado das redes públicas e privada, os homens passam a ser maioria. Na educação infantil e nos anos iniciais do fundamental, a distribuição por sexo é praticamente indistinta entre as redes públicas e privada. A partir dos anos finais do fundamental, entretanto, a participação masculina é sempre maior na rede privada.

O percentual de professores que se declara branco é majoritário nas redes públicas e privada e em todas as etapas, salvo na EJA nas redes públicas. Nota-se que o percentual de brancos, em todas as etapas de ensino, é maior na rede privada do que nas públicas, exceto no ensino médio integrado. A maior diferença encontra-se nos anos iniciais do ensino fundamental: as redes públicas apresentam $54,8 \%$ de professores brancos e a privada, $67,5 \%$. 
Nas duas redes, a média de idade dos professores é superior a 35 anos em todas as etapas de ensino. Nota-se que os professores da educação infantil (média de 41 anos nas redes públicas e 36 anos na rede privada) são mais jovens do que nas outras etapas de ensino (média de 42 anos nas redes públicas e entre 38 e 40 anos na rede privada). Além disso, os professores das redes públicas, em geral, são mais velhos do que os da rede privada.

Portanto, em sua maioria, os professores são mulheres brancas que cursaram educação superior e possuem em torno de 40 anos de idade. Essas características são mais frequentes entre os professores do que na população geral entre 25 e 50 anos, na qual as mulheres são $52 \%$, os brancos são $43 \%$, os formados com graduação na educação superior, $18 \%$, e a média de idade é um pouco menor, 37 anos.

\section{Proporção de professores e alunos}

Esta seção apresenta dados que permitem contextualizar o tamanho do corpo docente no Brasil vis-à-vis o contingente de alunos.

O Quadro 3 apresenta a relação entre matrículas e número de professores em duas etapas agregadas: a primeira abrange a educação infantil e os anos iniciais do ensino fundamental, enquanto a segunda abrange os anos finais do ensino fundamental e o ensino médio. Essa separação entre os níveis de ensino se justifica pelas diferentes funções e atribuições do professor. Na educação infantil e nos anos iniciais, em função da legislação existente, é mais comum haver a figura do professor regente, responsável por uma turma e várias disciplinas, ao passo que, nos anos finais e ensino médio, tipicamente, cada professor oferece uma disciplina a várias turmas.

Quadro 3. Relação entre matrículas e número de docentes - Brasil, $2017^{1}$

\begin{tabular}{|c|c|c|c|c|c|}
\hline \multicolumn{2}{|c|}{ Educação Infantil e Anos Iniciais } & \multicolumn{3}{c|}{ Anos Finais e Ensino Médio } \\
\hline Matrículas & Docentes & $\begin{array}{c}\text { Matrículas } \\
\text { por docente }\end{array}$ & Matrículas & Docentes & $\begin{array}{c}\text { Matrículas } \\
\text { por docente }\end{array}$ \\
\hline 23.732 .054 & 1.223 .790 & 19,39 & 19.943 .859 & 994.470 & 20,05 \\
\hline
\end{tabular}

Fonte: MEC/Inep. Elaboração: IDados. 2018.

O total de docentes neste quadro não necessariamente se iguala aos anteriores apresentados neste trabalho porque os docentes podem ministrar aulas para mais de uma etapa de ensino. 
O Quadro 3 permite observar que a razão entre matrículas e docentes é bastante semelhante nas duas etapas. Assim, ainda que as duas etapas apresentem demandas diferentes de disciplinas, a distribuição de docentes permite que a quantidade de matrículas por professor não se altere.

O Quadro 4 apresenta dados mais detalhados sobre a razão de matrículas e professor em cada etapa da educação básica, separando por redes públicas e privada. Com exceção da EJA e de Outros, em todos os demais níveis, a razão entre matrículas e professores é maior nas redes públicas de ensino. As redes públicas apresentam um pico nos anos iniciais do ensino fundamental, em que há 21,5 matrículas para cada professor. No entanto, a discrepância entre redes é maior no ensino médio, nível em que para cada professor de escola privada há 9,4 alunos, ao passo que para cada professor de escola pública há 16,9 alunos, ou seja, $80 \%$ a mais. Cabe observar que nas escolas privadas, o contrato de professores, tipicamente, se faz por horas/aula, e não por turnos parciais ou completos de trabalho, como nas redes públicas.

Quadro 4. Relação entre matrículas e número de docentes - Brasil, 2017

\begin{tabular}{|l|c|c|c|c|c|c|}
\hline & \multicolumn{2}{|c|}{$\begin{array}{c}\text { Matrículas } \\
\text { (em milhares) }\end{array}$} & \multicolumn{2}{c|}{$\begin{array}{c}\text { Docentes } \\
\text { (em milhares) }\end{array}$} & \multicolumn{2}{c|}{$\begin{array}{c}\text { Matrículas } \\
\text { por docente }\end{array}$} \\
\cline { 2 - 7 } & $\begin{array}{c}\text { Redes } \\
\text { Públicas }\end{array}$ & $\begin{array}{c}\text { Rede } \\
\text { Privada }\end{array}$ & $\begin{array}{c}\text { Redes } \\
\text { Públicas }\end{array}$ & $\begin{array}{c}\text { Rede } \\
\text { Privada }\end{array}$ & $\begin{array}{c}\text { Redes } \\
\text { Públicas }\end{array}$ & $\begin{array}{c}\text { Rede } \\
\text { Privada }\end{array}$ \\
\hline Educação Infantil & $6.144,2$ & $2.354,0$ & 389,9 & 168,8 & 15,8 & 13,9 \\
\hline $\begin{array}{l}\text { Ensino Fundamental - } \\
\text { Anos Iniciais }\end{array}$ & $12.485,7$ & $2.748,1$ & 581,8 & 177,9 & 21,5 & 15,4 \\
\hline $\begin{array}{l}\text { Ensino Fundamental - } \\
\text { Anos Finais }\end{array}$ & $10.224,5$ & $1.790,0$ & 631,2 & 151,4 & 16,2 & 11,8 \\
\hline Ensino Médio & $6.519,0$ & 950,8 & 384,7 & 101,0 & 16,9 & 9,4 \\
\hline Ensino Médio - Integrado & 440,5 & 19,0 & 52,3 & 2,7 & 8,4 & 7,0 \\
\hline EJA & $3.369,9$ & 170,8 & 234,2 & 7,3 & 14,4 & 23,4 \\
\hline Outros & 537,2 & 854,3 & 46,4 & 52,0 & 11,6 & 16,4 \\
\hline
\end{tabular}

Fonte: MEC/Inep. Elaboração: IDados. 2018.

Nota: "Outros" engloba educação especial e educação profissional.

Para complementar o cenário de atendimento dos professores, o Quadro 5 apresenta a razão entre turmas e professores nos diferentes níveis de ensino, nas redes públicas e na rede privada. O que se observa é que o número de turmas por professor se reduz com o aumento da série, de tal modo que a relação na 
educação infantil é maior que no ensino médio. Com exceção dos anos finais do ensino fundamental e do ensino médio, a razão turma por docente é maior ou igual na rede privada relativamente às redes públicas, devido à forma de contratação por hora/aula. As redes públicas apresentam um pico na educação infantil e nos anos iniciais do ensino fundamental, em que há 0,9 turmas para cada professor.

Quadro 5. Relação entre turmas e número de docentes - Brasil, 2017

\begin{tabular}{|l|c|c|c|c|c|c|}
\hline \multirow{2}{*}{ Ciclo } & \multicolumn{2}{|c|}{ Turmas } & \multicolumn{2}{c|}{ Docentes } & \multicolumn{2}{c|}{$\begin{array}{c}\text { Turmas por } \\
\text { Docente }\end{array}$} \\
\cline { 2 - 7 } & Redes & Rede & Redes & Rede & Redes & Rede \\
\cline { 2 - 7 } & Públicas & Privada & Públicas & Privada & Públicas & Privada \\
\hline Educação Infantil & 333.563 & 180.857 & 389.916 & 168.76 & 0,9 & 1,1 \\
\hline $\begin{array}{l}\text { Ensino Fundamental - } \\
\text { Anos Iniciais }\end{array}$ & 528.878 & 152.449 & 581.766 & 177.93 & 0,9 & 0,9 \\
\hline $\begin{array}{l}\text { Ensino Fundamental - } \\
\text { Anos Finais }\end{array}$ & 433.077 & 75.893 & 631.152 & 151.44 & 0,7 & 0,5 \\
\hline Ensino Médio & 210.787 & 33.987 & 384.711 & 101 & 0,5 & 0,3 \\
\hline Ensino Médio Integrado & 14.931 & 864 & 52.272 & 2.734 & 0,3 & 0,3 \\
\hline EJA & 129.417 & 5.737 & 234.186 & 7.287 & 0,6 & 0,8 \\
\hline Outros & 24.434 & 44.346 & 46.41 & 52.028 & 0,5 & 0,9 \\
\hline
\end{tabular}

Fonte: MEC/Inep. Elaboração: IDados. 2018.

Nota: "Outros" engloba educação especial e educação profissional.

Nota-se que a razão turma/professor corrobora o resultado encontrado no Quadro 1. Neste, nas primeiras etapas de ensino, a proporção de professores que trabalha em um único turno é maior nas redes públicas, assim como a relação de turmas por professor é menor nessas redes. Nos anos finais, a parcela de professores que trabalha em mais de um turno é maior, assim como a relação turma-professor fica menor nestas etapas.

Em relação à adequação da formação docente, o Quadro 6 apresenta a porcentagem de turmas que possuem professor com formação na etapa ou matéria que leciona. Seguindo a Nota Técnica N 20/2014 do MEC (INEP, 2014), para educação infantil e anos iniciais, define-se como tendo formação adequada os professores que fizeram o curso normal/magistério, os que possuem curso superior de licenciatura em Pedagogia, Língua Portuguesa, Arte, Educação Física, Matemática, Ciências, Química, Física, Biologia, Estudos Sociais, História, Geografia, Sociologia, Filosofia e Ensino Religioso, e os que fizeram o bacharelado nos mesmos cursos 
e que, adicionalmente, fizeram a complementação pedagógica. Para os anos finais e o ensino médio, são apresentadas porcentagens por matéria. Define-se como possuindo formação adequada os professores formados na matéria que lecionam. Vale destacar que, nos anos finais, há poucos professores que reportam lecionar Química, Física ou Biologia; em geral, essas matérias estão incluídas em Ciências.

O Quadro 6 mostra que cerca de $80 \%$ das turmas de educação infantil e anos iniciais possuem professores com formação adequada. Já, nos anos finais e no ensino médio, as porcentagens são menores, variando de 32,1\% em Física nos anos finais a 77,9\% em Educação Física no ensino médio.

Quadro 6. Adequação da formação docente: porcentagem de turmas cujo professor possui a formação adequada para a etapa/matéria

\begin{tabular}{|c|c|c|}
\hline Etapa/Matéria & $\%$ adequado & Número de turmas \\
\hline Educação Infantil & 70,9 & 1.060 .057 \\
\hline Anos Iniciais & 80,4 & 1.940 .217 \\
\hline \multicolumn{3}{|l|}{ Anos Finais } \\
\hline Língua Portuguesa & 69,9 & 498.826 \\
\hline Matemática & 62,2 & 483.378 \\
\hline Química & 39,9 & 8.840 \\
\hline Física & 32,1 & 9.626 \\
\hline Biologia & 67,1 & 6.237 \\
\hline Ciências & 66,7 & 466.878 \\
\hline História & 61,6 & 471.020 \\
\hline Geografia & 57,9 & 469.919 \\
\hline Educação Física & 68,0 & 476.257 \\
\hline \multicolumn{3}{|l|}{ Ensino Médio } \\
\hline Língua Portuguesa & 79,2 & 298.820 \\
\hline Matemática & 74,3 & 279.654 \\
\hline Química & 61,3 & 266.851 \\
\hline Física & 42,6 & 267.602 \\
\hline Biologia & 79,3 & 268.235 \\
\hline História & 69,5 & 265.720 \\
\hline Geografia & 71,1 & 264.177 \\
\hline Educação Física & 77,9 & 251.019 \\
\hline
\end{tabular}

Fonte: MEC/Inep. Elaboração IDados. Baseado em Nota Técnica Nº 020/2014. 
Os dados apresentados nessa seção se referem a um período em que as matrículas começam a se reduzir sensivelmente em função da mudança demográfica e, em parte, de medidas visando à correção do fluxo escolar (o número de turmas de correção de fluxo aumentou de 5.300 para 7.052 entre 2007 e 2017). A redução do tamanho das coortes prevista nas projeções do IBGE para as próximas décadas tornará esse quadro ainda mais dramático, no sentido de provocar um aumento do nível de ineficiência. Por outro lado, o mecanismo de contratações temporárias no setor público, e em regimes diferenciados de carga-horária, poderia servir como instrumento de correção para eventuais reduções do número de matrículas, no caso das redes públicas.

\section{Quanto ganham os professores em relação a outros profissionais}

Comparar salários de docentes com os de outras ocupações é problemático, por várias razões: a forma de contratação por turnos, a diferença entre horas contratadas e horas docentes, a quantidade de dias efetivamente trabalhados por ano, a definição do que seja o trabalho real - por exemplo, tempo de estudo, planejamento, correção de deveres escolares ou outras atividades na escola. Também entram na equação as características do trabalho, especialmente a aposentadoria especial, a duração do ano letivo e o número de horas por dia fora de casa. Ademais, comparações, levando em conta o salário-hora, semanal ou anual, certamente resultam em conclusões diferentes. Dessa forma, os dados apresentados nessa seção devem ser cuidadosamente interpretados.

O Gráfico 4 apresenta a média de horas trabalhadas por semana reportadas pelos trabalhadores das dez ocupações com maior número de pessoas empregadas com nível superior (dados da PNAD contínua). A linha vertical indica a média de horas trabalhadas para os professores da educação básica: 32,5 horas/semana. Nas demais ocupações, os resultados variam desde 35,2 para professores da educação superior até 45,6 para os comerciantes.

O Gráfico 5 compara as médias do salário-hora dos professores com as médias dessas mesmas dez ocupações do Gráfico 4. O salário-hora dos professores (redes públicas e privadas) é de R \$21,20 (linha vertical), ficando acima apenas do salário-hora médio das ocupações Escriturários, Balconistas e Vendedores, e Comerciantes. Todas as demais profissões mostradas no gráfico possuem salário-hora médio maior do que o de professores da educação básica.

O Gráfico 6 apresenta dados da PNAD e PNAD Contínua no período 2003-2017 e oferece um panorama da evolução nas diferenças salariais entre professores 
Professores de Educação Superior

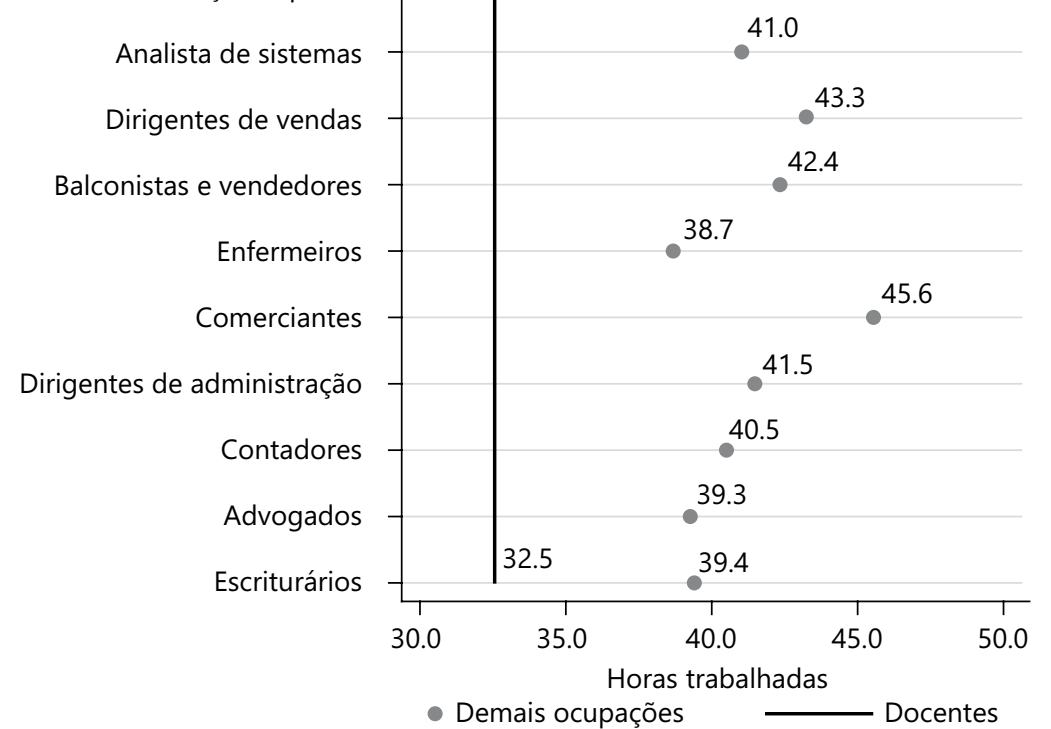

Gráfico 4. Média de horas semanais trabalhadas nas 10 ocupações mais empregadoras e professores - Brasil, 2017. Fonte: PNAD contínua 2017. Elaboração: IDados. 2018.

Professores de Educação Superior

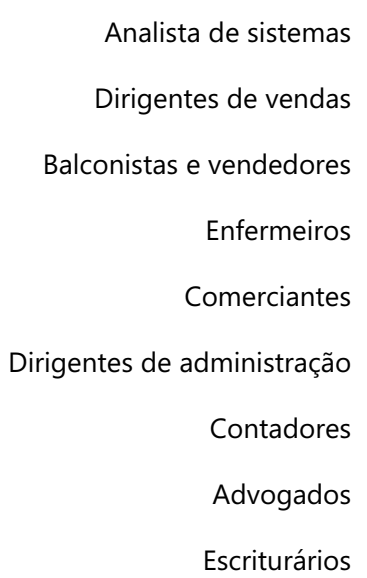

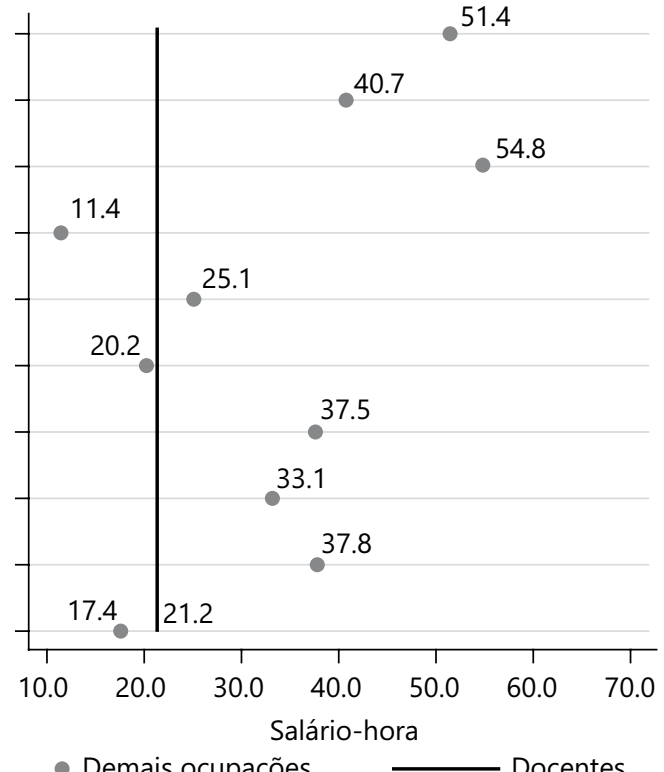

Gráfico 5. Salário-hora médio nas 10 ocupações mais empregadoras e professores Brasil, 2017. Fonte: PNAD contínua 2017. Elaboração: IDados. 2018. 
e outras ocupações. O gráfico mostra que, entre 2005 e 2017, a remuneração por hora dos professores esteve abaixo da auferida pelos outros profissionais com ensino superior. No entanto, observa-se que, ao longo do período, há uma tendência de queda na diferença salarial média entre os dois grupos: entre altos e baixos, os outros profissionais recebiam $86 \%$ a mais que os professores em 2005, mas essa diferença caiu para 53\% em 2017.

Desde a criação do Fundo de Manutenção e Desenvolvimento da Educação Básica e de Valorização dos Profissionais da Educação, o FUNDEF, no final do século $\mathrm{XX}$, diversas políticas vêm sendo implementadas para aumentar o salário dos professores, com ênfase no aumento do piso salarial, implementado em 2009, e na promoção de sistemas de carreira previstos, entre outros, na lei que estabelece o Plano Nacional de Educação (PNE).

O Gráfico 6 também apresenta a evolução do piso salarial para o magistério público. Desde a sua criação, em 2009, o piso sofreu um aumento real de $48 \%$, enquanto o salário-hora dos professores aumentou $17 \%$ e o salário dos outros profissionais reduziu-se em $3 \%$. Além dos salários dos professores apresentarem uma tendência de crescimento, enquanto as outras carreiras apresentaram relativa estagnação, 52\% dos municípios ofereciam, em 2008, um salário-hora abaixo do determinado em 2009 pelo piso salarial, indicando que esse aumento real dos salários dos professores pode ter alguma relação com o piso proposto (dados da Relação Anual de Informações Sociais - RAIS).

De toda forma, com a determinação de um piso salarial para os professores, uma indagação importante pode ser feita em relação à essa política: em que medida o piso salarial teria contribuído para uma possível redução na dispersão salarial entre professores?

O Gráfico 7 apresenta a evolução da dispersão do salário-hora dos professores da educação básica (medida pelo desvio-padrão), divididos em quatro faixas salariais correspondentes aos percentis 0-25, 26-50, 51-75 e 76-99 da distribuição de salários. Apesar da rede privada não estar sujeita ao piso salarial, o gráfico mostra que as duas redes apresentam um padrão de dispersão semelhante. Nas duas redes, nos três grupos salariais mais baixos, a dispersão é pequena e variou pouco no período. Já no grupo com maiores rendimentos, a dispersão é bem maior e aumentou ao longo do período nas duas redes, apesar de o salto ter sido maior nas redes públicas. Isso significa que, no grupo de professores com salários mais altos, a variação salarial é muito maior e as diferenças continuaram aumentando. 


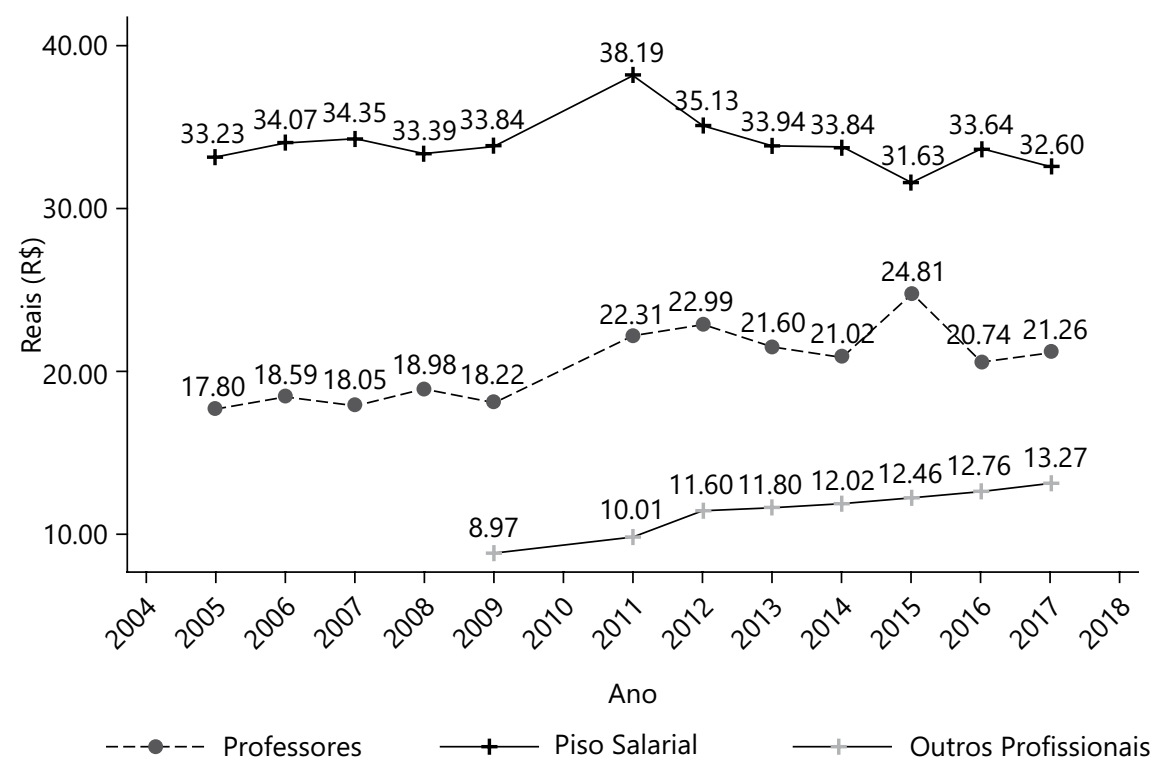

Gráfico 6. Evolução do salário-hora professores, outros profissionais com ensino superior e Piso salarial dos professores - Brasil, 2005 a 2017 a preços de 2017. Fonte: PNAD anual, PNAD contínua e IPCA/IBGE. Elaboração: IDados. 2018.
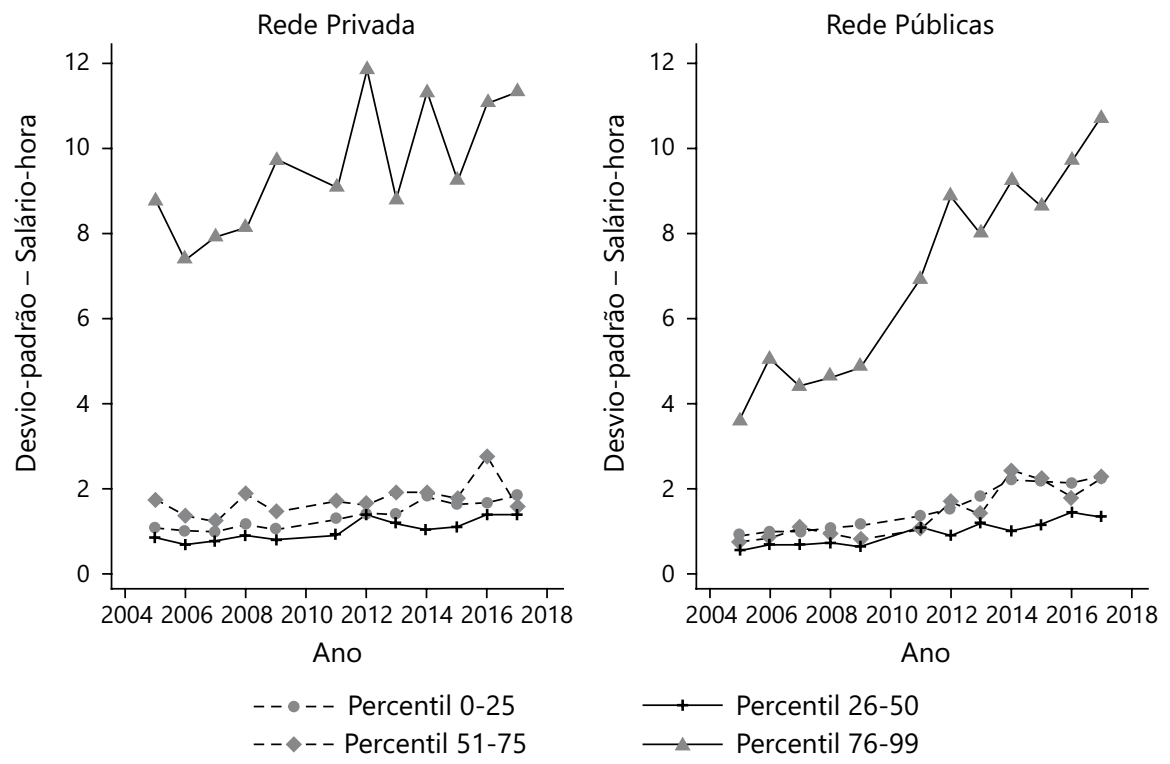

Gráfico 7. Evolução da dispersão do salário-hora dos professores por percentil para as redes pública e privada - Brasil, 2005 a 2017. Fonte: PNAD/IBGE - Elaboração IDados. 2018. 
Ao retomar a comparação entre professores e demais ocupações de ensino superior, destaca-se que, além das diferenças intrínsecas da profissão enumeradas no início desta seção, há outra possível explicação para o salário dos professores ser menor. Tal explicação seria o fato de que os candidatos que escolhem magistério apresentarem, de forma geral, desempenho inferior, nas provas do ENEM, ao de candidatos que procuram outras profissões.

O Gráfico 8 apresenta o percentual de alunos concluintes nos cursos avaliados pelo ENADE entre 2014 e 2016 que obtiveram nota no ENEM acima de 600 pontos. À exceção de Física, os cursos de licenciatura e Pedagogia estão entre os cursos com menores percentuais de alunos que obtiveram 600 pontos no ENEM, indicando que esses cursos estão captando os piores alunos que ingressam na educação superior. Nesse caso, se o desempenho no ENEM estiver correlacionado

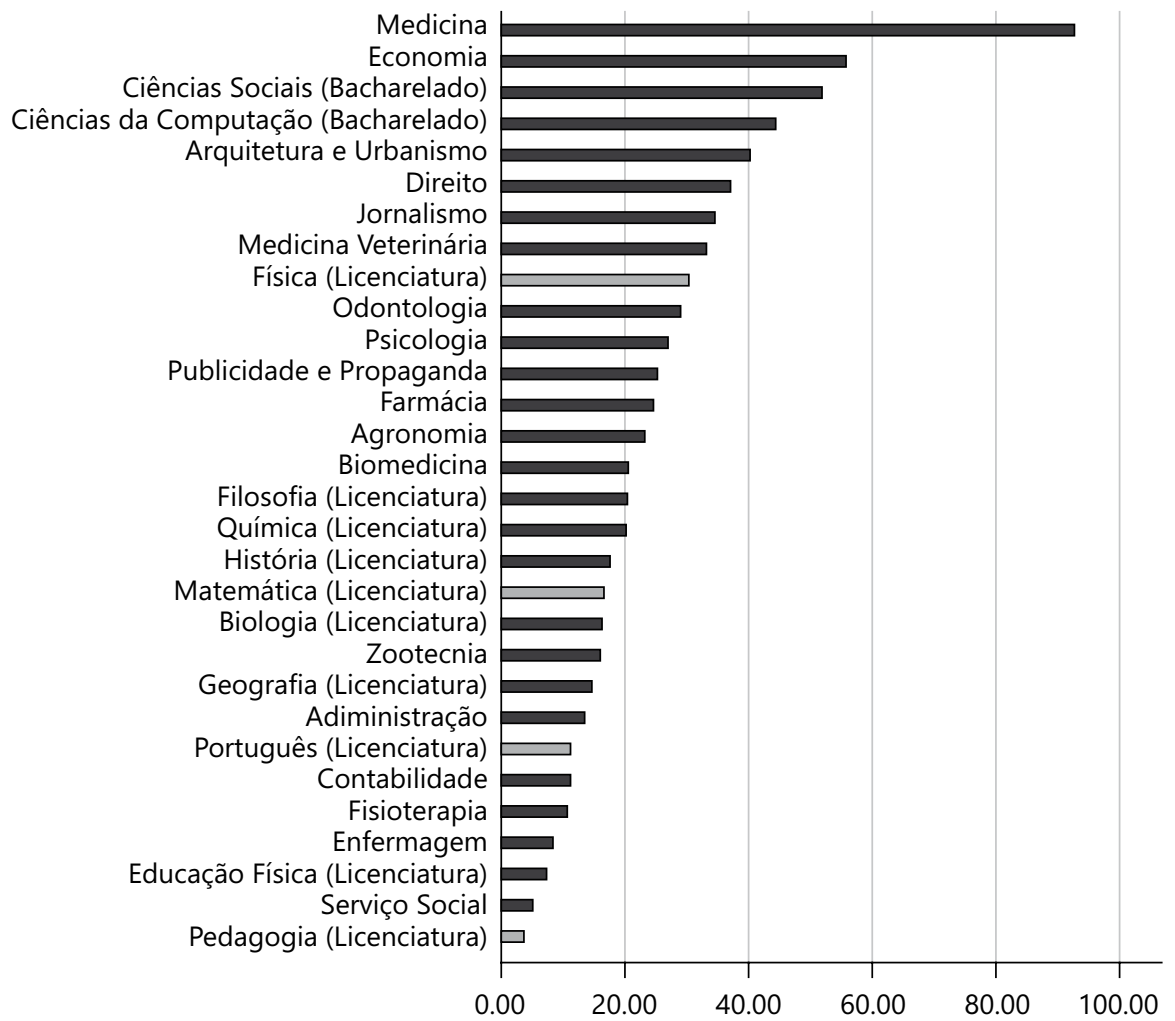

Gráfico 8. Proporção de concluintes que obtiveram nota acima de 600 pontos no ENEM - Brasil, 2014-2016. Fonte: Inep/MEC. IDD/ENADE. Elaboração IDados. 2018. 
com produtividade futura, os candidatos a professores receberiam salários menores depois de formados, independentemente, de terem escolhido ser professores ou não.

O Gráfico 9 apresenta uma comparação internacional com o intuito de contextualizar a situação do professor no Brasil com a de professores de países que, reconhecidamente, possuem um sistema de ensino de boa qualidade. O gráfico apresenta um indicador utilizado pela Organização para a Cooperação e Desenvolvimento Econômico (OCDE, 2018), a saber, a razão salário anual por PIB per capita, para analisar o nível de atratividade da carreira. O quadro foi complementado com o dado para o Brasil, calculado a partir dos dados da RAIS e do IBGE.

A relação entre salário e PIB per capita no Brasil é de 1,5, fato que o coloca entre os países com uma das maiores razões dentre os países analisados. Dessa forma,

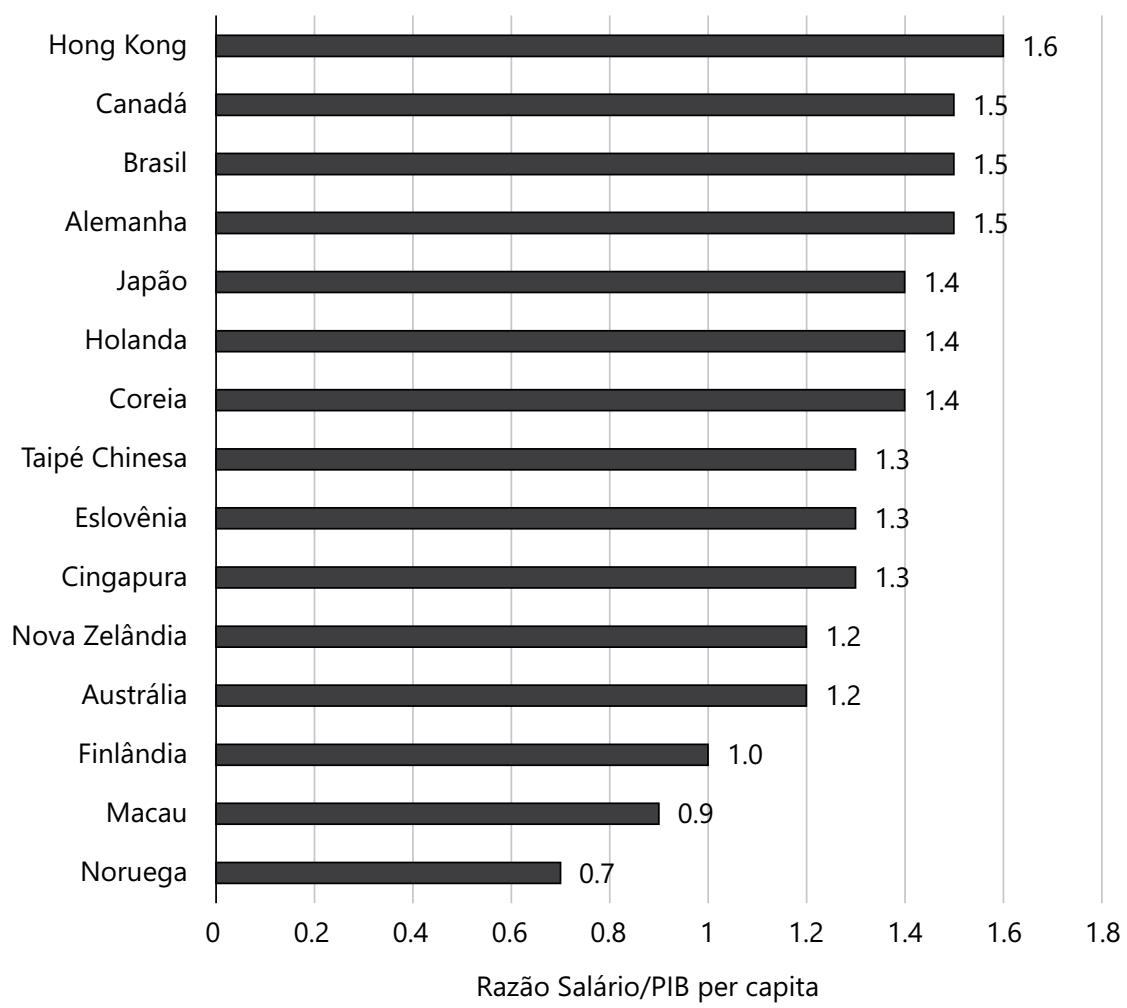

Gráfico 9. Razão Salário-PIB per capita - Países Selecionados - 2014. Fonte: OCDE (2018), RAIS, IBGE. 2018. 
ainda que os professores, por quaisquer motivos, recebam salário menores que outras profissões no Brasil, há que se debater sobre quanto, de fato, o salário influencia o acesso à carreira, pois essa segunda análise sugere que o magistério é uma carreira com salários relativamente atraentes. Nesse sentido, outros fatores explicariam a falta de atratividade da carreira por parte dos melhores alunos, como a atuação em áreas remotas, a falta de segurança dentro das escolas ou a falta de um plano de carreira mais elaborado que premie os professores baseados em sua atuação e esforço, e não apenas por sua antiguidade ou título.

\section{Discussão}

A ideia de que os professores do setor público devem ganhar salários compatíveis com o mercado está associada ao fato de que se espera que profissionais adequadamente remunerados contribuiriam para o melhor desempenho dos alunos. Ainda que não seja uma condição suficiente, ao menos seria uma condição necessária. Analisado sob outro prisma - seria um truísmo afirmar que para ter uma força de trabalho de alto nível é necessário que carreira e condições de trabalho, inclusive salários, sejam suficientes para atrair pessoas com o perfil desejado.

O Quadro 7 mostra a relação entre o salário dos professores e o desempenho dos alunos de $5^{\circ}$ e $9^{\circ}$ ano na Prova Brasil de Matemática em 2015. Cada linha mostra a diferença média entre a nota dos alunos cujos professores ganham mais de $\mathrm{R} \$ 6.780,00$ e a nota dos alunos cujos professores ganham o valor indicado em cada linha. Essa diferença é líquida, ou seja, estão descontados os efeitos de outras variáveis que podem estar associadas às notas dos alunos, como escolaridade da mãe e experiência do professor ${ }^{2}$. Nesse cálculo, não foram incluídos os professores da rede privada, uma vez que o objetivo é gerar evidências sobre custo-benefício para o setor público, que será discutido adiante.

O que se observa é que as diferenças são bastante modestas. O maior impacto estimado vem da comparação do desempenho de alunos do $5^{\circ}$ ano, cujo professor ganha até $\mathrm{R} \$ 678,00$, com um professor que ganha dez vezes mais, ou seja, $\mathrm{R} \$ 6.780,00$ ou mais. Nesse caso, a diferença é de 3,7 pontos a menos na prova para alunos cujos professores ganham menos. Nas séries finais, a maior diferença também aparece ao comparar os extremos: 3,2 pontos. Nota-se que a maioria das diferenças estimadas não é estatisticamente significante, ou seja, não se pode dizer

\footnotetext{
As diferenças reportadas são os coeficientes associados às faixas salarias de uma regressão linear estimada por Mínimos Quadrados Ordinários. A variável dependente é a nota do aluno em matemática, e as variáveis independentes são idade, sexo e cor ou raça do aluno, escolaridade da mãe, escolaridade, experiência e salário do professor, experiência e forma de contratação do diretor e dummies para regiões geográficas. Os erros-padrão foram estimados utilizando cluster no nível da turma.
} 
Quadro 7. Relação entre nota de matemática na Prova Brasil e faixa salarial do professor - comparação entre quem recebe acima de $\mathrm{R} \$ 6.780$ e demais faixas de remuneração - Brasil, 2015.

\begin{tabular}{|c|c|c|c|c|}
\hline \multirow{3}{*}{$\begin{array}{l}\text { Salário mensal reportado } \\
\text { Até } R \$ 678,00\end{array}$} & \multicolumn{4}{|c|}{ Diferença média em pontos na Prova Brasi } \\
\hline & \multicolumn{2}{|c|}{$5^{\circ}$ ano } & \multicolumn{2}{|c|}{$9^{\circ}$ ano } \\
\hline & -3.7 & $* * *$ & -3.2 & ** \\
\hline Entre $R \$ 679,00$ e $R \$ 1.017,00$ & -2.1 & * & -0.1 & \\
\hline Entre $R \$ 1.018,00$ e $R \$ 1.356,00$ & -1.4 & & -1.2 & \\
\hline Entre $R \$ 1.357,00$ e $R \$ 1.695,00$ & -0.6 & & 0.5 & \\
\hline Entre $R \$ 1.696,00$ e $R \$ 2.034,00$ & 0.4 & & -0.2 & \\
\hline Entre $R \$ 2.035,00$ e $R \$ 2.373,00$ & 0.5 & & 0.1 & \\
\hline Entre $R \$ 2.374,00$ e $R \$ 2.712,00$ & 1.5 & & 0.3 & \\
\hline Entre $R \$ 2.713,00$ e $R \$ 3.390,00$ & 0.7 & & 1.6 & $* * *$ \\
\hline Entre $R \$ 3.391,00$ e $R \$ 4.746,00$ & 0.8 & & 0.8 & * \\
\hline Entre $R \$ 4.747,00$ e $R \$ 6.780,00$ & 0.4 & & -0.1 & \\
\hline
\end{tabular}

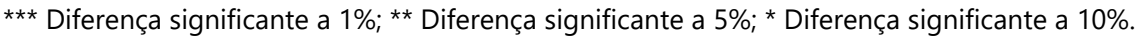
Fonte: MEC/INEP. Elaboração IDados. 2018.

que as diferenças encontradas são diferentes de zero para 15 das 20 diferenças estimadas. Isso significa que o salário recebido tem pouca ou nenhuma correlação com o desempenho dos alunos do $5^{\circ}$ e $9^{\circ}$ ano.

Portanto, mesmo que o salário dos professores de menor ganho (abaixo de R $\$$ $1.018,00$ ) sofra um aumento de 1,5 vezes, por exemplo, gerando um custo anual de quase $\mathrm{R} \$ 1$ bilhão ${ }^{3}$, o impacto no desempenho dos alunos das séries iniciais seria menor que 0,1 de um desvio-padrão. Em paralelo, Bruns e Luque (2014) mostram que a diferença no IDEB entre as $10 \%$ melhores escolas e as $10 \%$ piores do Rio de Janeiro, que certamente diferem em mais de $1 / 4$ de um desvio-padrão no desempenho, está associada a um melhor uso do tempo na sala de aula: enquanto nas melhores escolas os professores passam 70\% do tempo de aula ensinando, nas piores escolas essa porcentagem é de 54\%. Ao final de um ano letivo (200 dias), isso significa 32 dias a mais de instrução. Ou seja, esse resultado sugere que seria possível melhorar o desempenho dos alunos apenas melhorando a gestão do tempo do professor em sala de aula.

$3 \mathrm{R} \$ 1.187-\mathrm{R} \$ 848=339,00 \times 2.192 .224 \times 0,062$ (professores $\times$ proporção de professores na Prova Brasil na faixa de renda) $\times 13$ (doze meses mais $13^{\circ}$ salário) + $R \$ 1.187-R \$ 678=509,00 \times 2.192 .224 \times 0,023 \times 13$. Para realização das estimativas, considerou-se o ponto médio de salário dentro de cada faixa 
Essas evidências não sugerem que os salários de professores devam ser limitados a R \$ 1.356,00 (valor a partir do qual não há efeito sobre nota - Quadro 7). Tampouco, sugere que um salário de $\mathrm{R} \$ 1.356,00$ assegure bom desempenho dos alunos. A evidência apenas indica que a relação entre salário e desempenho é fraca e que, mesmo no caso dos salários mais elevados, o impacto que pode ser esperado no desempenho dos alunos, a partir de um foco apenas em salários, é relativamente modesto. O relatório Coleman da década de 1960 (COLEMAN; CAMPBELL; HOBSON, 1966) já mostrava que as diferenças socioeconômicas entre alunos explicavam a maior parte do desempenho escolar nos EUA, argumento corroborado por Hanushek (2007), anos depois. Loeb e Page (2000), por exemplo, estimaram que aumentar os salários dos professores em $10 \%$ reduz as taxas de abandono escolar em apenas 3\% a 4\%. Assim, a experiência internacional sugere que uma eventual reforma da carreira de magistério, embora passe por uma revisão da política salarial, não deveria ter como foco a remuneração, mas, sim, outros fatores que poderiam influenciar, direta ou indiretamente, na qualidade do ensino de uma forma mais geral, incluindo, por exemplo, formação inicial e continuada adequadas e adequação da formação do professor.

A interpretação desses dados pode ser feita por analogia ao que a literatura apresenta em relação a gastos com educação: gastos podem fazer diferença no desempenho até certo limiar, a partir do qual, outros fatores passam a ser mais importantes. Por exemplo, entre 1970 e 1994, os países da OCDE dobraram ou triplicaram os gastos reais em educação sem que tenha havido avanços no desempenho dos alunos (PRITCHETT, 2004). Dados mais recentes da OCDE (MOURSHED; CHIJIOKE; BARBER, 2010) mostram que, até atingir gastos de 6.000 dólares $\mathrm{PPP}^{4}$, o desempenho dos alunos desses países varia desde os níveis mais baixos aos níveis mais elevados.

Ganimian e Murnane (2014), em uma revisão da literatura sobre sistemas de incentivo em países em desenvolvimento, concluem que são raros os casos em que os sistemas de incentivo levam a um aumento significativo, sistemático e sustentável do desempenho. No entanto, os autores reportam alguns casos de sucesso, como o da redução do absenteísmo dos professores na Índia (DUFLO; HANNA; RYAN, 2012). Os autores concluem que a estrutura de incentivo importa mais do que o tamanho do incentivo. Por sua vez, Hanushek (2011) mostra que um dos mecanismos mais eficazes para melhorar o desempenho dos alunos foi excluir, anualmente, os professores cujos alunos estavam no nível mais baixo de desempenho (5\% "piores professores"). No Brasil, Bruns, Evans e

\footnotetext{
4 Dólares Paridade do Poder de Compra, ou Dólares PPP, é uma conversão realizada para comparação de valores em moedas que circulam em diferentes países.
} 
Luque (2012) apontam melhoras expressivas em indicadores de comportamento dos professores e de resultados dos alunos em um experimento com bônus por desempenho em Pernambuco.

Na maioria das redes públicas do Brasil, medidas de desempenho dos alunos (seja em proficiência, seja em aprovação) influem pouco ou nada na remuneração, nos reajustes salariais ou nas promoções, além de não poderem influir em demissões, no caso de servidores estatutários. De modo geral, isso deriva da lei 8.112, que dispõe sobre o regime jurídico dos servidores públicos e que estabelece o princípio da isonomia. Isso limita a capacidade do Estado de atrelar remuneração a desempenho escolar, mantendo experiência e títulos acadêmicos como os principais determinantes da remuneração (BRUNS; EVANS; LUQUE, 2012), ainda que, em alguns casos, o bônus anual seja equivalente a quase um salário mensal (LÈPINE, 2016). No entanto, muitos estudos mostram que tais fatores não guardam relação com o desempenho dos alunos. Glewwe et al. (2013), em uma revisão da literatura para o período de 1990 a 2010 para países em desenvolvimento, reportam que, de 63 estimativas do efeito da experiência sobre proficiência, apenas 17 são positivas e significantes estatisticamente. No caso de títulos, das 6 estimativas encontradas, apenas duas são positivas e significantes. Por outro lado, $55 \%$ das estimativas (18 de 33 ) a respeito do efeito do nível de conhecimento do professor acerca do assunto lecionado (medido por meio de testes) encontram efeitos positivos e significantes.

Duas recentes análises (BANCO MUNDIAL, 2017; MOURSHED; CHIJIOKE; BARBER, 2010) reconhecem o fato de que muitos países conseguem melhorar a eficácia de ensino por meio de outras medidas ou "reformas" educativas. Tipicamente, o baixo desempenho também está associado ao baixo nível de preparo dos professores. Em situações como essa, intervenções que sistematizam o currículo, o ensino e a prática dos professores tendem a propiciar aumentos significativos nos resultados dos alunos (Singapura seria um exemplo). Todavia, esses estudos observam que, ao mesmo tempo em que os países de sucesso adotavam essas medidas, também foram desenvolvidas novas estratégias para recrutar e formar melhores professores, o que serviu de base para avançar em suas reformas educativas e no grau de autonomia atribuído às escolas.

\section{Conclusão}

Este artigo apresentou o perfil dos professores da educação básica no Brasil. A partir de dados de diversas fontes, foi possível quantificar o contingente de professores e caracterizá-los quanto às suas características socioeconômicas e demográficas, bem como quanto aos fatores associados à profissão, como turno 
e redes de trabalho. Foram apresentadas também diversas tendências em relação ao número de professores e sua remuneração.

Em linhas gerais, o professor trabalha 32,5 horas por semana em apenas uma rede de ensino e turno. O típico profissional de ensino é mulher, branca, com 40 anos de idade e salário-hora médio de $\mathrm{R} \$ 21,20$. O número de professores aumentou, consideravelmente, nos últimos 15 anos, contrastando com a redução no número de matrículas. Finalmente, chama a atenção o número de profissionais na educação de jovens e adultos (234 mil em 2017), cerca de 60\% do número de professores alocados no ensino médio.

Os dados apresentados nesse estudo indicam que os professores recebem, em média, menos que outros profissionais com educação superior no Brasil. Por outro lado, o nível de atratividade da carreira, estimado por meio da razão entre salário e PIB per capita, está entre os mais altos comparativamente a países que possuem sistemas de ensino de boa qualidade, como Alemanha e Canadá. No entanto, como observado, a carreira tem atraído indivíduos com um perfil de formação que possivelmente é insuficiente para promover um avanço na qualidade do sistema educativo. São necessários mais estudos nessa área, para que se possa compreender melhor esse aparente paradoxo.

Finalmente, os dados apresentados sugerem que, por um lado, aumentar o salário dos professores nessa condição tem custos altos e impacto reduzido sobre o desempenho dos alunos. Por outro lado, para melhorar o nível de desempenho dos alunos com esses professores, talvez sejam mais adequadas estratégias similares ao conceito de "lean operations", utilizadas no mundo da gestão: qualquer sistema de produção deve combinar insumos e processos para lograr um determinado resultado (ou produto). Quando a qualidade dos insumos é baixa, o sistema de produção precisa usar processos rigorosos para obter produtos de qualidade. Se a qualidade do input é elevada, o sistema de produção precisa flexibilizar os processos para produzir o mesmo output. Em um esforço de reforma educativa, isso significa, primeiro, estabilizar o sistema e, depois, colocá-lo na rota que the permita obter melhorias constantes. 


\section{Teachers: who they are, where they work, how much they earn}

\section{Abstract}

Teachers are one of the most relevant inputs of the educational system. Teacher's profile, wage, working conditions and teaching methods contribute to student performance. This paper analyzes the most current data available on Brazilian teachers: who they are, where they work, how much they earn, their impact on students. This information is essential to understand the reality, the trends and possibilities of intervention. The paper is divided in three parts. The first characterizes the number of teachers by level of education and presents data regarding their profile. The second part presents data regarding the wage profile and recent salary trends. The third part discusses the actual and potential impact of teachers. The paper concludes with reflections on possible ways to increase the efficiency and effectiveness of public education, but possibly also of the private sector.

Keywords: Basic education. Teachers. Wage.

\section{Profesores: quiénes son, dónde trabajan, cuánto ganan}

\section{Resumen}

Los profesores constituyen uno de los componentes más relevantes en el proceso educativo. El perfil, la remuneración, las condiciones de trabajo y la forma de actuación de los profesores contribuyen de manera significativa al desempeño de los estudiantes. El presente artículo analiza los datos más actuales disponibles sobre los profesores brasileños: quiénes son, dónde trabajan, cuánto ganan, qué impacto producen. Estas son informaciones esenciales para entender la realidad, las tendencias y las posibilidades de intervención. El estudio se divide en tres partes. En la primera se caracteriza la cantidad de profesores por nivel de enseñanza y presenta datos acerca de su perfil. En la segunda parte se presentan datos sobre la remuneración y las tendencias recientes de aumento de los salarios. En la tercera se discute el impacto real y potencial de los profesores en un sistema de enseñanza. El articulo concluye con reflexiones acerca de posibles caminos para aumentar la eficiencia y la eficacia de las redes públicas de enseñanza y, posiblemente, también de la red particular.

Palabras clave: Educación básica. Profesores. Salario. 


\section{Referências}

ANDRADE, E. R. et al. O perfil dos professores brasileiros: o que fazem, o que pensam, o que almejam. São Paulo: Unesco/Moderna, 2004.

BANCO MUNDIAL. Um ajuste justo: análise da eficiência e equidade do gasto público no Brasil. Brasil: Síntese, 2017. Vol. 1.

BARBOSA FILHO, F. H.; PESSÔA, S. A.; AFONSO, L. E. Um estudo sobre os diferenciais de remuneração entre os professores das redes pública e privada de ensino. Estudos Econômicos, v. 39, n. 3, p. 597-628, jul/set. 2009. https//doi.org/10.1590/S0101-41612009000300006

BARROS, R. P.; MENDONÇA, R.; BLANCO, M. O mercado de trabalho para professores no Brasil. In: ENCONTRO NACIONAL DE ECONOMIA - ANPEC, 29., Salvador, BA, 2001. Anais... Disponível em: <https://ideas. repec.org/p/anp/en2001/099.html>. Acesso em: 14 dez. 2018.

BRUNS, B.; EVANS, D.; LUQUE, J. Achieving world-class education in Brazil: The next agenda. Washington DC: The World Bank, 2012.

BRUNS, B.; LUQUE, J. Professores excelentes: como melhorar a aprendizagem na América Latina e no Caribe. Brasília, DF: Banco Mundial, 2014.

COLEMAN, J. S., E. Q. CAMPBELL, AND C. J. HOBSON. Equality of educational opportunity. Washington, DC: U.S. Government Printing Office, 1966.

DEMO, P. Rupturas urgentes em educação. Ensaio: Avaliação e Políticas Públicas em Educação, v. 18, n. 69, p. 861-71, Dec. 2010. https://doi.org/10.1590/S0104-40362010000400011

DUFLO, E; HANNA, R.; RYAN, S. P. Incentives work: getting teachers to come to school. American Economic Review, v. 102, n. 4, p. 1241-78, jun. 2012.

FAJARDO, I. N.; MINAYO, M. C. S.; MOREIRA, C. O. F. Educação escolar e resiliência: política de educação e a prática docente em meios adversos. Ensaio: Avaliação e Políticas Públicas em Educação, v. 18, n. 69, p. 761-73, Dec. 2010. https://doi.org/10.1590/S0104-40362010000400006 
GANIMIAN, A.J.; MURNANE, R.J. Improving educational outcomes in developing countries: Lessons from rigorous evaluations. Cambridge: National Bureau of Economic Research, 2014.

GLEWWE, P. W. et al. School resources and educational outcomes in developing countries: a review of the literature from 1990 to 2010. In GLEWWE, P. W. Education policy in developing countries. Chicago: The Chicago University Press, 2013. p. 13-64.

HANUSHEK, E. A. Assessing the effects of school resources on student performance: an update. Educational Evaluation \& Policy Analysis, v. 19, n. 2, p. 141-64, 2007. https://doi.org/10.2307/1164207

HANUSHEK, E. A. The economic value of higher teacher quality. Economics of Education Review, v. 30, n. 3, p. 469-79, june 2011. https://doi.org/10.1016/j.econedurev.2010.12.006

INSTITUTO NACIONAL DE ESTUDOS E PESQUISAS EDUCACIONAIS ANÍSIO TEIXEIRA - INEP. Nota Técnica $N^{\circ} 020 / 2014$. Indicador de adequação da formação do docente da educação básica. Brasília, DF, 2014.

LÈPINE, A. Teacher incentives and student performance: evidence from Brazil. Working Papers, Department of Economics, University of São Paulo, 201618.

LOEB, S.; PAGE, M. E. Examining the link between teacher wages and student outcomes: the importance of alternative labor market opportunities and non-pecuniary variation. Review of Economics and Statistics, v. 82, n. 3, p. 393-408, Aug. 2000.

MOURSHED, M.; CHIJIOKE, C.; BARBER, M. How the world's most improved school systems keep getting better. London: Mckinsey \& Company, 2010.

OCDE. Effective teacher policies: insights from PISA. Paris: OECD, 2018. Disponível em https://read.oecd-ilibrary.org/education/effective-teacherpolicies_9789264301603-en\#. Acesso em: 14 dez. 2018.

PIMENTEL, G. S. R.; PALAZZO, J.; OLIVEIRA, Z. R. B. B. Os planos de carreira premiam os melhores professores. Ensaio: Avaliação e Políticas Públicas em Educação, v. 17, n. 63, p. 355-80, abr.jun. 2009. https://doi.org/10.1590/S0104-40362009000200009 
PRITCHETT, L. Access to education. IN: LOMBORG, B. Global crises, global solutions. Cambridge: Cambridge University Press, 2004. p. 175-234.

RODRIGUES, S. S. Eficácia docente no ensino da matemática. Ensaio: Avaliação e Políticas Públicas em Educação, v. 25, n. 4, p. 114-47, jan,/mar. 2017. https://doi.org/10.1590/s0104-40362017000100005

\section{Informações sobre os autores:}

Guilherme Hirata: Doutor em Economia pela Pontifícia Universidade Católica do Rio de Janeiro (PUC-Rio), pesquisador do IDados. Contato: guilherme@idados.org.br

João Batista Araujo e Oliveira: Doutor em Pesquisa Educacional pela Florida State University (FSU), presidente do Instituto Alfa e Beto. Contato: jmeduc@gmail.com

Talita de Moraes Mereb: Mestre em Economia pela Fundação Getúlio Vargas - EPGEFGV, pesquisadora do IDados. Contato: talita@idados.org.br

Agradecimentos: Os autores agradecem a Érika Dias (editora) e dois pareceristas anônimos por comentários e sugestões. Agradecem ainda a Dayhane Paes e João Rebouças pelo auxílio prestado em diversas etapas deste projeto. 